Southern Illinois University Edwardsville SPARK

SIUE Faculty Research, Scholarship, and Creative Activity

Winter 1-2019

\title{
Snapchat and Civic Engagement among College Students
}

Laurie Rice

Southern Illinois University Edwardsville, larice@siue.edu

Kenneth Moffett

kmoffet@siue.edu

Follow this and additional works at: https://spark.siue.edu/siue_fac

Part of the American Politics Commons, Communication Technology and New Media

$\underline{\text { Commons, }} \underline{\text { Social Influence and Political Communication Commons, and the Social Media }}$ Commons

\section{Recommended Citation}

Rice, Laurie and Moffett, Kenneth, "Snapchat and Civic Engagement among College Students" (2019). SIUE Faculty Research, Scholarship, and Creative Activity. 98.

https://spark.siue.edu/siue_fac/98

This Article is brought to you for free and open access by SPARK. It has been accepted for inclusion in SIUE Faculty Research, Scholarship, and Creative Activity by an authorized administrator of SPARK. For more information, please contact magrase@siue.edu. 


\section{Cover Page Footnote}

"This is an Accepted Manuscript of an article published by Taylor \& Francis in The Journal of Information Technology and Politics in January 2019, available online: http://www.tandfonline.com/10.1080/

19331681.2019.1574249. 


\title{
Snapchat and Political Engagement Among College Students
}

\author{
Laurie L. Rice \\ Department of Political Science \\ Southern Illinois University Edwardsville \\ 3234 Peck Hall, Box 1453 \\ Edwardsville, Illinois 62026 \\ (618) 650-2075 \\ larice@siue.edu \\ and \\ Kenneth W. Moffett \\ Department of Political Science \\ Southern Illinois University Edwardsville \\ 3234 Peck Hall, Box 1453 \\ Edwardsville, Illinois 62026 \\ (618) 650-2649 \\ kmoffet@,siue.edu
}

September 30, 2018

Prepared for submission to the Journal of Information Technology and Politics

A previous version of this paper was presented at the 2017 Annual Meeting of the American Political Science Association. We thank Grete Graf, Michael Jensen and Nannihal Singh for providing helpful suggestions and comments. All errors and omissions remain our own. 


\section{Snapchat and Civic Engagement Among College Students}

During the 2016 presidential election cycle, Clinton and Trump used Snapchat as one part of their overall voter outreach and engagement efforts. This portion of their campaign strategy was disproportionately targeted toward younger voters, since those between 18 and 25 comprise a vast portion of Snapchat's user base. Did their efforts, those of political parties, or those of interest groups on Snapchat produce higher

levels of civic engagement among college students? We utilize a survey that we conducted from a college campus in the Midwest in October 2016 to answer this question. Using a series of matching analyses, we discover that those students who sent pictures or videos about interest groups, candidates for office, or political parties on Snapchat were more civically and politically active than otherwise similar students who had not participated in these activities. 
During the run-up to the 2016 general election, several candidates used Snapchat as part of their outreach to potential voters. Rand Paul launched a Snapchat account in January 2014 (Chittal, 2015) and used it to upload video of himself taking a chainsaw to the U.S. tax code (Lapowsky, 2016). Jeb Bush's official campaign kickoff rally was on Snapchat Live, with Snapchat staff curating uploads, giving viewers behind-the-scenes glimpses of the rally, and helping them feel as if they were there (Chittal, 2015). During the same week as Jeb Bush's rally, Snapchat offered "Hello, Hillary 2016" as a live story from her New York rally (Chittal, 2015). In addition, Bernie Sanders ran a nine-day campaign during the Iowa caucuses as a follow-up to appearing in a Live feature (Piper, 2016).

Hillary Clinton and Donald Trump used Snapchat throughout the 2016 election, as both had Snapchat geofilters available for their campaign rallies (Miller, 2016; Piper, 2016). The Clinton campaign purchased several anti-Trump geofilters for the Republican National Convention including one with yellow police tape that read "Stop Trump" (Piper, 2016). Not to be outdone, the Trump campaign purchased filters for the first presidential debate, one of which announced the debate as being between Donald J. Trump and "Crooked Hillary," with a backdrop of fireworks and a row of stars across the bottom followed by Trump's campaign slogan of "Make America Great Again” (Miller, 2016).

Clinton’s chief digital strategist, Teddy Goff, acknowledged that “...it’s incumbent upon us as a campaign to find ways to be authentically fun and interesting if we want to have any hope of earning their attention on Snapchat" (Piper, 2016). Amid the attention-getting behavior both campaigns engaged in during the 2016 campaign on Snapchat, a question arises: did these actions have impacts on political participation that extended beyond the moments of levity, novelty or entertainment they injected into the presidential campaign? If Snapchat has an impact, then is its impact unique relative to other social media forms?

Examining Snapchat use among young adults is important because this app reached over $41 \%$ of those between the ages of 18 and 34 as of September 2015 (Snapchat Ad Page, 2016). In addition, Snapchat reported that purchased geofilters like those mentioned earlier can reach between 40 and 60 percent of Snapchat users (Boorstin, 2016). This brought the candidates' filters and messages to a 
potentially broad audience of young adults. But, do the politically relevant activities that younger voters perform on Snapchat lead to higher levels of political activity away from the internet? If so, which political uses of Snapchat lead to greater levels of other forms of civic engagement?

To explore these questions, we begin with an overview of Snapchat's history and its use in the 2016 presidential election. Then, we develop a case for why political uses of Snapchat may facilitate higher levels of civic engagement among young adults. We use data from a 2016 survey of randomly chosen 18-25 year-olds at a university located in the Midwest to test our theory. ${ }^{1}$ We find that what some may dismiss as a passing fad with limited impact ends up having important and broader consequences for young adult participation.

\section{Snapchat and Elections}

Snapchat resulted from a partnership between Stanford students in the same fraternity, one of whom pitched the idea to a class in 2011 (Wortham, 2013). Its initial appeal to users was its disappearing content because senders could use their smartphones to send a picture to someone and set it to disappear within one to ten seconds of being viewed (Piwek and Joinson, 2016). The only record of the photo that remained on either phone, barring intervention from outside the app, was a timestamp when an unidentified object was sent from the sender's device (Piwek and Joinson, 2016).

Soon, the ability to use a variety of filters, doodles, and stickers increased its user base. Chat and video chat features followed in 2014, as did geofilters tied to a user's location (Nusca, 2017). Also in 2014, Snapchat began hosting Live events where users at the event (as determined by their phones'

\footnotetext{
${ }^{1}$ This dataset appropriately tests the theory because Snapchat had the youngest user base out of the nine leading social media platforms in 2014, with $45 \%$ of its adult users reported by comScore to be between the ages of 18 and 24 (Bump, 2015). Snapchat's growth has been dramatic - by year's end 2015, its user base climbed to 100 million and it grew even further to 150 million in 2016 (Nusca, 2017). This user base remains skewed towards young adults (Duggan, 2015).
} 
location services) upload ten-second snaps and curators at Snapchat make a small fraction of these available on the Live platform to all Snapchat users for 24 hours (Verstraete, 2016).

In 2015, Snapchat launched Discover, where a variety of media partners, including CNN, ESPN, and National Geographic, could post content specifically aimed at Snapchat users every 24 hours. It also hired Peter Hamby, a former political reporter for CNN, to head its news division (Mahler, 2015). Outlets on Discover quickly drew large numbers of viewers (Bump, 2015). Moreover, he developed educational content for Snapchat about how the election works that helped prepare young users to participate in their first presidential election (Flynn, 2016). Under his direction, Snapchat added several election-focused Discover channels (Flynn, 2016). Additionally, Snapchat used its older tools to encourage participation in the presidential election, offering users geofilters that remind people to vote and a "Go Vote" bitmoji (Boorstin, 2016).

As the 2016 election approached, Snapchat harnessed its tools in other ways that promote civic engagement. Snapchat Chief Executive Officer Evan Spiegel stated that, "The thing that excited us is we really saw an opportunity to not only help politicians reach constituents, but really to help people learn about politics in a way that goes beyond just knowledge, like just reading about it or hearing from a singular newscaster" (Bump, 2015). In the lead up to the 2016 general election, Snapchat offered numerous Live events connected to the presidential campaign, including the conventions and debates. Snapchat reported that nearly twice the number of young adults watched the first debate between Republican candidates on Snapchat than on television (Rutenberg, 2016). While they watched later debates between Trump and Clinton, viewers could place filters on the candidates or swap out their faces to amuse themselves, helping young adults engage with politics in a new way (Friesleben, 2016).

Snapchat hired Rob Saliterman, Google's former head of political advertising, to convince campaigns to use Snapchat (Flynn, 2016; Lapowsky, 2016). Initially, this appeared to be a tough sell because Snapchat lacks many of the campaign-friendly features that Facebook and Twitter have. For instance, user data are private, user networks tend to be small, ads can only be targeted down to the state level, and advertisers only receive a few basic metrics like number of unique views and completion rates 
(Lapowsky, 2016). ${ }^{2}$ Yet, one of Snapchat's key selling points to campaigns is its ability to reach young adults with ads that fill the screen. Thus, some strategists view it as a viable alternative to television advertising for reaching young voters (Lapowsky, 2016), while others liken it to lawn signs seen by millions of young adults (Bump, 2015). Bump (2015) identified three ways for politicians to reach young adults: convince users to add the politician on Snapchat, buy ads on Discover, or buy ads in Live stories.

Beyond the efforts of campaigns to reach voters, Snapchat also created Live events that helped its users feel part of the election, including "Voting Day" at polling booths, election night watch parties, and in a nod to its young user base "Colleges React" (Flynn, 2016). Snapchat allowed users to process the election results by uploading their reactions for potential use in a Live feed curated by journalists (Flynn, 2016). Both Snapchat and the campaigns did a lot to gain the attention of young adults and increase their engagement. Did these efforts work? We consider this question in the following sections by focusing on how political uses of Snapchat promote civic engagement, a term we use to describe participation in both political and civic life.

\section{Social Media and Civic Engagement}

Young adults have been lambasted for decades for their low levels of political engagement. Both exit polls and surveys routinely report young adults engaging in far lower percentages of voting and other traditional forms of political participation than their elders (Miller and Shanks, 1996; Zukin, Keeter, Andolina, Jenkins, and Delli Carpini, 2006; Holbein and Hillygus, 2016). When engagement is broadened to include civic activities like volunteering for community groups, this age gap appears somewhat reduced but still present (Zukin, Keeter, Andolina, Jenkins, and Delli Carpini, 2006). A variety of explanations have been offered for this pattern including life cycle effects (Erkulwater, Schlozman, Verba, and Brady, 2012) and generational differences in world views or conceptions of what makes a good citizen (Jennings and Niemi, 1981; Putnam, 2000; Dalton, 2008; Wattenberg, 2011) Whatever its

\footnotetext{
${ }^{2}$ Further, campaigns must rely on Snapchat staff to discover their number of followers and since links cannot be posted, it is difficult to use the app to recruit volunteers or solicit campaign contributions (Chittal, 2015).
} 
cause, this pattern leaves younger Americans underrepresented in civic and political life and has potential consequences for both responsiveness to the concerns of this age group and the nation's long term civic and political health.

However, social media shows some promise in reducing age gaps in participation. Many researchers discovered that varying forms of social media are connected with higher levels of civic engagement among young adults (Cantijoch, Cutts, and Gibson, 2016; Conroy, Feezell, and Guerrero, 2012; Gil de Zuniga, Jung and Venezuela, 2012; Rice, Moffett and Madupalli, 2013; Towner, 2013; Xenos, Vromen, and Loader, 2014). For example, some have found that higher levels of online news consumption are associated with increased political participation (Shah, Kwak, and Holbert, 2001; Kenski and Stroud, 2006). In part, this link exists because political information is easily accessible to young adults through social media. By obtaining political information online, young adults readily obtain the political knowledge needed to participate.

Others have identified opportunities for higher levels of political participation through the outlets for political expression available via social media. The internet and social media provide new forums for communicating and spreading political information, allowing users to gain greater self-efficacy and both the knowledge and skills needed to participate (Kenski and Stroud, 2006; Shah, McLeod, and Lee, 2009; Gil de Zuniga, Bachmann, Hsu, and Brundidge, 2013; Moffett and Rice, 2018). Among young adults, many have found that Facebook and Twitter lead to greater levels of offline and online civic engagement (Cantijoch et al, 2016; Conroy et al, 2012; Gil de Zuniga et al, 2012; Rice et al, 2013; Towner, 2013; Xenos et al, 2014).

While both routes can lead to greater participation, prior research suggests expressive uses offer more direct routes to participation than do informational uses. For example, Gil de Zuniga et al (2013) find differential effects of political blog use based on whether that use is consumptive or expressive; consuming political blogs does not have a direct relationship with political participation while using blogs to express oneself about politics does. Similarly, Moffett and Rice (2016) find a direct relationship 
between tweeting about politics and greater offline civic engagement but not between following political tweets and offline civic engagement.

\section{Snapchat and Information Processing}

Although it provides expressive and consumptive outlets for political participation, many researchers have not examined Snapchat use, and the research that exists is relatively limited. For example, early news stories on Snapchat use focused on teenagers' use of it for sexting (Vaterlaus, Barnett, Roche and Young, 2016). Yet, focus groups of young adult and adult users found few reported using Snapchat in this fashion (Vaterlaus, Barnett, Roche and Young, 2016). Surveys show users report turning to it most frequently for distraction, procrastination, and sending selfies and humorous photos (Utz, Muscanell and Khalid, 2015).

At first glance, Snapchat operates at a disadvantage when it comes to promoting participation because it is known for its disappearing content. Users typically allow content to be viewed for between one and ten seconds and Discover and Live events disappear after 24 hours. Ordinarily, images and information that are fleeting might be dismissed as having little chance to have an impact. Yet, Snapchat's disappearing content encourages users to focus on the content and process what they are viewing (boyd, 2014; Piwek and Joinson, 2016). Rutenberg (2016) notes that Snapchat was created for young adults bombarded with a "constant stream of bits and bytes," unable to process everything. Thus, Snapchat's disappearing content may be an advantage when it comes to promoting participation because it encourages users to quickly read, watch, share, or respond.

If true, then this line of reasoning is consistent with the tenets of information processing theory. This theory provides additional insights regarding the connection between activities on Snapchat and civic activity. To begin, this theory presumes that people have limited processing capacity, making attention a scarce resource (Kahneman, 1973). For information to have any impact, there must be exposure, followed by attention (Kahneman, 1973; Mitchell, 1983). Without these early steps, persuasion is impossible (McGuire, 1978). Millennials are used to multitasking, but Snapchat makes that harder. danah boyd (2014) argues that Snapchat's functionalities promote attention: 
In a digital world where everyone's flicking through headshots, images, and text without processing any of it, Snapchat asks you to stand still and pay attention to the gift that someone in your network just gave you. As a result, I watch teens choose not to open a Snap the moment they get it because they want to wait for the moment when they can appreciate whatever is behind that closed door. And when they do, I watch them tune out everything else and just concentrate on what's in front of them. Rather than serving as yet-another distraction, Snapchat invites focus.

Thus, Snapchat provides a vehicle for generating Millennial attention to the presidential campaign, a necessary first step toward action.

This theory also states that people devote less attention and processing capacity to advertising when they perceive no need for information (Mitchell, 1983), but are more apt to process information they consider personally relevant (Kuiper and Rogers, 1979). Through election-related Discover channels, Snapchat engages in efforts to convince Millennials that they need information about the election and that it is personally relevant. Then, Snapchat supplies 10 second ads purchased by campaigns that consume users' smartphone screen. While users can look away, ten seconds does not offer much time to do something else when one's personal device has been temporarily commandeered by a political ad. Snapchat's continued growth and the popularity of its Live events suggests this attention is a small price to pay to continue viewing desired content. Thus, Snapchat not only provides a vehicle for attention, but helps move the needle towards attention to presidential campaigns.

Snapchat encourages users to be "in the moment," mimicking face-to-face interaction in some ways (Verstraete, 2016). Unlike Facebook Live or other forms of social media that make content available indefinitely, Snapchat's limited time horizon for viewing information encourages users to make time for it now. This, too, promotes greater information processing. Piwek and Joinson $(2016,365)$ argue that "...the combination of self-destructing images with an immersive interface that restricts the scope of user interaction with the content makes Snapchat an instant narrative vehicle that is similar to verbal story exchange." This creates a personal connection with the information shared on Snapchat that carries over into Live events. While these events are viewable for 24 hours, the curated footage shot from users' smartphones combined with special behind the scenes access helps Snapchat users feel what it is like to be there in person. During the 2016 election, millions of Snapchat users could see and vicariously 
experience the kickoffs of presidential campaigns, campaign rallies, and candidate debates Live without being physically present. These events made the election more accessible and personally relevant, drawing Millennials' attention in new ways.

Like other social media platforms, Snapchat allows viewers to engage in real time expression about campaign-related content that they view on television. This practice of second screening (Giglietto and Selva, 2014) can help increase processing of information beyond attention to elaboration and lead to greater civic engagement. For example, tweeting about debates as they unfold and using Twitter hashtags to join debate-related conversations increases civic engagement and facilitates conversations with strangers (Vacarri, Chadwick, and O'Laughlin, 2015). Yet, compared to other social media platforms with larger social circles, Snapchat's disappearing content and personal connections may give senders of political content greater assurance that recipients will watch, listen, or view their messages.

\section{Snapchat and Civic Engagement}

Snapchat can be used to perform multiple functions that may have differing impacts on civic engagement when users adapt them for political purposes. Snapchat's functions can be divided into passive, consumptive activities like monitoring political content posted by others or active, expressive activities like sharing political pictures or videos or chatting about politics. Monitoring political content may be passive but it provides users an opportunity to gain the knowledge needed to participate. If both Snapchat's and political campaigns' intentional efforts to help young adults learn about politics worked to enhance participation, then monitoring political content posted on Snapchat should lead to greater levels of offline political participation.

Snapchat also provides several ways to communicate about politics that range from using the chat function to creating and sharing content. Sharing selfies superimposed with filters that allow one to look like Clinton, complete with hairstyle and pantsuit (Tulip, 2016), or sharing images during the debate of Trump with a flower crown or Clinton with bunny ears (Friesleben, 2016) with young adults' closest friends or family may seem humorous and trivial. Yet, these uses may encourage political expression, even among those who normally have little interest in politics. If simply providing vehicles for political 
expression heightens offline political participation, then all three expressive uses of Snapchat should be associated with greater offline participation. If, instead, both Snapchat's and political campaigns' efforts to provide creative and innovative ways to share political content increased participation, then sharing political pictures and video via Snapchat should lead to engaging in higher levels of offline participation, but there would not be an expected rise in participation among those who use it to chat about politics.

\section{Data}

We performed an online survey of randomly selected, full-time undergraduate students between the ages of 18 and 25 at a Midwestern public university that has approximately 14,000 students between October 11 and 25, 2016. We acquired the entire list of university-assigned student e-mail addresses from this University's Office of Institutional Research and Studies to compose our sample. Each student was sent an e-mail that introduced the study and was given a unique link to complete the survey. To encourage survey participation, we sent three follow-up emails to students on October 18, October 23, and a final one on October 25. Approximately 933 of the 9,576 students that were eligible to complete the survey did so. To incentivize student participation in the survey, respondents were entered in a drawing to win a free iPad. The response rate for our survey (about 9.7\%) lies within the range that other entities have provided (see Pew 2016). ${ }^{3}$

Our sample roughly mirrors that which exists in the population at this university. For example, our sample is $59.23 \%$ female while the population is $54.18 \%$ female. Also, our sample is $81.92 \%$ whites while the population is $72.8 \%$ whites. Moreover, our sample is $9.69 \%$ African Americans while the population is $13.2 \%$ African Americans. Finally, the mean age of our undergraduate students in the same is 21.12 years, while the population average is $21.00 .^{4}$

\footnotetext{
${ }^{3}$ The margin of error for this survey is $3.79 \%$.

${ }^{4}$ That said, it is possible that differences between the sample and population drive our results. To account for this possibility, we weighted the observations by race and sex and re-ran our analyses. The signs and significance
} 


\section{Dependent Variable}

The dependent variable is the rate with which each student participated in political and civic activities away from the internet. Each respondent was asked about the frequency with which they have engaged in each of twelve different activities that ranged from "very often" to "never" using a five-point scale. These activities include having contacted a newspaper, radio or TV talk show to express one's opinion on an issue; participating in protests, marches, or demonstrations; and working with a group to solve a community problem. Then, to create a single measure of political and civic activity, we added the values for each of the twelve activities to generate an index that was based on answers to this set of questions $(\alpha=.83, \mathrm{M}=10.94, \mathrm{SD}=7.12) .{ }^{5} \mathrm{We}$ use a series of matching analyses to test our theoretical expectations. Appendix A in the Online Appendix provides a more detailed discussion of the variables that we used including question wording.

\section{Treatment Variables}

We utilized four different variables to determine the effects of Snapchat on civic engagement. We asked whether each respondent had monitored what a candidate for political office, political party, or a political group posted on Snapchat during $2016(\mathrm{M}=.67, \mathrm{SD}=1.13) .{ }^{6} \mathrm{We}$ also asked respondents whether they had sent a picture $(M=.54, S D=1.05)$, video $(M=.41, S D=.98)$, or chatted $(M=.57, S D=1.02)$ with

patterns of those analyses are identical to those reported in Tables One and Two with one exception: frequently sending pictures loses significance ( $\mathrm{p}=.118$ ). The complete set of results are available in Appendix D, Tables D2 through D6.

${ }^{5} \mathrm{M}$ denotes the mean for that variable, while SD signifies the standard deviation for that variable.

${ }^{6}$ We performed a confirmatory factor analysis to examine whether the measures of activity on Snapchat are consistent with one another. It is possible that these measures of activity differ so substantially from one another that it does not make sense to analyze them altogether. The confirmatory factor analysis provides strong evidence that these treatments are consistent with one another with a reasonably fitted model such that they can be analyzed in the way that we do so here. These results are contained in Table D1 in Appendix D of the Online Appendix. 
someone else via Snapchat about a candidate for office, political party, or a political interest group in 2016. Each of these questions was asked on a five-point scale that ranged from zero for never having done so to four for having performed these activities very often.

\section{Matching Covariates}

We used four variables to investigate the effects of general political engagement on civic activity. First, each student was asked how frequently s/he read internet blogs about politics and current events on a five-point response scale $(\mathrm{M}=1.51, \mathrm{SD}=.87)$ for which zero points were allocated to "Not at all," and four points for "Very often", as Kerbel and Bloom (2005) suggest that blogs can act as vehicles by which to enhance civic engagement. Second, each respondent was asked about the extent to which s/he paid attention to presidential campaigns during the 2016 election cycle $(\mathrm{M}=2.59, \mathrm{SD}=1.11)$, as Norris (2002) finds that attention to campaigns is connected to higher levels of political activism. We used a five-point scale for this question, with values that ranged from zero points for "Not at all interested," to four points for "Very interested."

Third, we asked each student about the extent to which s/he is interested in politics on a fourpoint scale $(\mathrm{M}=1.84, \mathrm{SD}=.87)$ ranging from zero points for "Not at all interested," and three points for "Very interested." ${ }^{7}$ Fourth, we constructed an additive index to investigate the effects of peer civic experiences on civic engagement based on three questions that examined the extent to which each respondent's friends engaged in a set of activities $(\mathrm{M}=7.36, \mathrm{SD}=2.47)$. Each of the items were answered

\footnotetext{
${ }^{7}$ It is possible that interest in politics, strong partisanship and being a political science major are so interrelated that they add little to the analyses. To consider this possibility, we removed each of these variables one at a time to investigate whether our results change. The results largely mirror what is reported here. The results for removing one of interest in politics, strong partisanship and political science major are furnished in Appendix C.
} 
on a five-point response scale that ranged from zero points for "strongly disagree," to four points for “strongly agree" $(\alpha=.68){ }^{8}$

Additionally, we employed six variables to measure the effects of personal characteristics on civic engagement. First, we account for the strength of each respondent's partisan attachment because this is connected with other forms of political activity (see, e.g., Flavin and Griffin, 2009; Rosenstone and Hansen, 1993; Verba, Brady and Schlozman, 1995). To measure the extent of partisanship among respondents, each student was asked whether s/he identifies as a Republican, Democrat, independent or something else. Using two questions with slightly modified wording, each student who self-identified as a Democrat or Republican was asked whether s/he strongly or not strongly identified as a Democrat or Republican, respectively. Based on the responses, we generated a binary variable that is coded one for those who have strong partisan attachments $(\mathrm{M}=.36, \mathrm{SD}=.48)$. Second, we created a dichotomous variable for political science majors based on a question about student major(s) in our surveys $(\mathrm{M}=.05, \mathrm{SD}=.48)$, as students who major in this subject area can have higher levels of civic engagement (Conroy et al, 2012).

Third, we investigated the effects of ideology on civic activity, as others have discovered that identifying as a conservative or liberal shapes some forms of participation (Achen and Bartels, 2016; Best and Kruger, 2005). Each student was asked whether s/he self-identifies as a moderate, liberal, conservative, something else, or does not know. If the respondent replied, "unknown" or "don't know," then we followed up with a question about whether that person identifies themselves as a liberal or conservative if they were forced to choose. Based on replies to both questions, we created binary

\footnotetext{
${ }^{8}$ These were the only questions asked about peer civic experiences. Some respondents responded that they did not know for these questions. When constructing our index, we coded values for these variables as missing. Thus, there is no peer civic engagement score for those who answered "don't know" for at least one of the questions.
} 
variables for conservatives $(\mathrm{M}=.27, \mathrm{SD}=.44)$ and liberals $(\mathrm{M}=.35, \mathrm{SD}=.48) .{ }^{9}$ For instance, the binary for liberals is coded one when the respondent replied that s/he was a liberal or self-identified as a liberal in the follow-up question that was directed to those students who did not know their ideology. ${ }^{10,11}$ Fourth, we asked each student their sex, and coded this binary variable one for females and zero for males $(\mathrm{M}=.59, \mathrm{SD}=.49)$. Finally, we gathered data on the age of each respondent by asking each student to report their month and year of birth. Then, we computed each student's age based on the month and year of the 2016 general election $(\mathrm{M}=21.15, \mathrm{SD}=1.58) .{ }^{12}$

\section{Methods}

To determine whether activities on Snapchat are connected with offline civic engagement, we need to determine an average treatment effect on the treated (ATET). A matching analysis estimates an ATET while a regression-based approach does not. If we solely relied on OLS estimates to obtain our results, our results may be biased because any estimate is conditioned on other values of the remaining covariates.

Moreover, individuals have diverging probabilities of engaging in differing levels of political activity on Snapchat. An OLS estimator presumes treatment homogeneity, which does not hold here as it is possible that individuals have different effects, particularly depending on their level of treatment (see Abadie and Imbens, 2011). Thus, the effects of a politically-based activity on Snapchat vary depending on the extent to which that respondent engaged in that activity. For instance, those who send politically-

\footnotetext{
${ }^{9}$ Our surveys do not contain a measure that allows us to determine the strength of ideological attachment. That said, considering ideology in the manner that we do allows us to investigate the effect of ideological direction on civic engagement.

${ }^{10}$ We coded the dummy variable for conservatives using the same process.

${ }^{11}$ Collectively, the comparison category for both binary variables is political moderates.

${ }^{12}$ Unfortunately, we lack additional, relevant variables about socioeconomic status such as a student's (or alternatively, their family's) income.
} 
oriented pictures on Snapchat very often are likely to engage in offline civic activities more frequently than those who rarely send such pictures on Snapchat. By construction, an OLS-based estimator presumes that we observe a linear, homogeneous relationship between sending politically-oriented pictures on Snapchat and offline civic activity. A matching-based approach deals effectively with this issue because it assumes neither homogeneity nor linearity, and allows for several treatment estimates depending on the level of treatment that a respondent received (Imbens and Rubin, 2015). Thus, we can generate several, more precise estimates of the effect that each level of every activity on Snapchat has on offline civic activity.

Third, OLS does not allow us to estimate what happens to offline civic activity in the absence of politically-oriented activities on Snapchat (Nichols, 2007). A matching analysis utilizes the existing data to generate a dataset that includes observations that are as similar as possible based on the values of the remaining covariates (Stuart, 2010). This allows us to estimate the counterfactual of what would have happened in the absence of a politically-oriented activity on Snapchat (see Gelman and Hill, 2007). Then, we estimate the effects of a level of a politically-based activity on Snapchat on offline civic activity using this dataset. Finally, we repeat this procedure for each level of each politically-based activity on Snapchat.

Matching analyses rectify each of these issues because they permit us to examine whether varying levels of sending pictures or videos on Snapchat is connected with higher levels of other forms of civic engagement. By matching based on each of the control variables to make inferences, we can separate the impact of both Snapchat-based activities beyond individuals' other inclinations to participate. Thus, doing so allows us to compare people with similar predispositions to civic engagement who vary only in their Snapchat use. Moreover, matching allows us to calculate ATETs for each level of each treatment, and by doing so, to gain more accurate effect estimates using observational data.

\section{Assumptions}

We must meet four assumptions prior to performing matching, as the validity of any analyses performed using this technique depends greatly on satisfying these assumptions. First, we presume that each treatment variable (e.g., sending pictures or videos on Snapchat) is binary. To make our treatment 
variables dichotomous, we generated a series of binaries for each response option, relative to never having done so. These binaries are coded one for each of these categories, zero for never having done so, and missing for those who do not have a Snapchat account, declined to answer the question, and for the remaining scalar options. For instance, there are binaries for rarely doing an activity on Snapchat, sometimes doing so, frequently engaging in this activity, and doing so very often. ${ }^{13}$ In total, there are sixteen binary variables because we have four treatments (monitoring Snapchat posts, engaging in politically-oriented chatting, sending pictures and videos) and four levels at which the treatment is analyzed (rarely, sometimes, regularly, and very often), relative to never having done one or more of these activities. We expect positive signs for the ATET for each variable.

Second, we assume overlap (or common support), which means that it shall be possible that treated units could face an intervention that may have assigned them to the control group (see Imbens and Rubin, 2015; King, Lucas and Nielsen, 2017). The data that we use fulfill this requirement because all respondents could have chosen not to engage in any of the Snapchat-based political activities.

Third, we must meet the stable unit treatment value (SUTVA) assumption, which means that, "The potential outcomes for any unit do not vary with the treatments assigned to other units, and for each unit, there are no different forms or versions of each treatment level, which lead to different potential outcomes" (Imbens and Rubin, 2015, 10). Part one of this assumption is satisfied because civic activity does not vary with the levels of snapchat engagement in which other individuals engage. ${ }^{14}$

\footnotetext{
${ }^{13}$ For example, the binary for rarely having monitored is coded one for those who rarely did so, zero for never having done so, and missing for those without Snapchat accounts, declined to answer the question, and those who responded that they had sometimes, regularly, or very often monitored what candidates for office, political parties, or interest groups post on Snapchat.

${ }^{14}$ If civic engagement were related to the decisions of others to engage in one or more activities on Snapchat, then we would observe high correlations between one or more of these activities and offline civic engagement. To test this, we correlated our dependent variable (offline civic engagement) and each of our treatment variables
} 
The second portion of this assumption is more intricate because we have different variations on each treatment variable: never, rarely, sometimes, frequently, and very often. Yet, we can compare the effects of engaging in each higher level of a Snapchat-based action to those who had never engaged in that action. For instance, we can compare those who had rarely engaged in a Snapchat-based action to those who had never engaged in that action, if we exclude those who had sometimes, regularly, or very often engaged in that action from that analysis. ${ }^{15}$ We must perform an analogous procedure to compare those who had sometimes, frequently, or engaged in each Snapchat-based activity very often if we hope to perform a matching analysis without an alternative treatment. When we execute our estimations in this way, we end up satisfying the SUTVA assumption because we have no interference, and we have no hidden variations of the treatments (Imbens and Rubin, 2015, 10-11).

Finally, the assignment to treatment must be conditionally independent of the response variable given an array of independent variables (D'Agostino, 1998, 2266). By implication, each respondent's assignment to any of the treatments (e.g., sending a picture or a video on Snapchat) is unconnected with their level of civic activity, given the values of the remaining independent variables. We observe a broad range of participatory levels with respect to civic engagement, and the mean level of civic engagement is reasonably low, given the minimum (2) and maximum values (42) possible with this index. Moreover, the activities that comprise offline civic engagement do not cause a person to be assigned to one or more treatment categories.

(monitoring, sending a picture, sending a video, or chatting with someone on Snapchat). The correlations that we observed are $.34, .37, .42$, and .37 , respectively. These correlations are sufficiently low such that we can say that the first portion of the SUTVA assumption is fulfilled.

${ }^{15}$ If we do not do this, then we cannot satisfy SUTVA, as there would be alternative forms of the treatment (see Imbens and Rubin, 2015, 10-13). 


\section{Matching Technique}

Once we have satisfied the statistical assumptions that underlie matching, we need to select a method by which to perform matching. We use one-to-one genetic matching with replacement to perform our matching analyses (Diamond and Sekhon, 2013; Sekhon, 2011), while incorporating a propensity score into the analysis, as knowing estimated values of this score greatly improves the accuracy of this method (Diamond and Sekhon, 2013). Matching with propensity scores allows us to compare observations that are otherwise similar on other covariates, but have experienced different treatments. We perform our analysis with replacement, as matching discrepancies are smaller because we can use untreated units as a match multiple times (see Abadie and Imbens, 2006). ${ }^{16}$ Finally, we perform our matching with a bias correction to eliminate any bias that arises due to the choice of the matching estimator without affecting the variance of that estimator (Abadie and Imbens, 2016).

\section{Results}

Before discussing the results, we must analyze the extent to which the treatment and control groups are similar (King, et al, 2017). If these groups are substantially imbalanced, then we cannot use matching to estimate effect size. The imbalance statistics for the models that follow are contained in Tables B1 through B10 in Appendix B of the Online Appendix. In every case, the Kolmogorov-Smirnov (KS) tests are not significant at the .05-level after matching has occurred. Thus, we are confident that we have reduced imbalance and have achieved balance, as the minimum t-test $\mathrm{p}$-value after matching across all specifications is .095. When we observe this pattern, it shows that, "the corresponding distributions for the matched groups are similar across all covariates" (Eggers and Hainmueller, 2009, 521). In addition, the matched groups have similar characteristics that we observe, such that any remaining differences

\footnotetext{
${ }^{16}$ However, we do not perform a regression following the matching analysis (as Ho et al, 2007 suggest), as Abadie and Spiess (2016) state that this is inappropriate when matching is done with replacement as researchers obtain inaccurate standard error estimates.
} 
across varying levels of Snapchat-based activities can be attributed to the effect of the activities and not to preexisting differences (Eggers and Hainmueller, 2009).

\section{[TABLES ONE AND TWO ABOUT HERE]}

\section{[FIGURE ONE ABOUT HERE]}

Tables One and Two displays the effect sizes from each of the matching routines for our four dependent variables. The results indicate that some political activities on Snapchat are connected with higher levels of civic activity away from that medium while others are not. The results in Table One indicate that monitoring politically-oriented Snapchat posts or politically-oriented chatting on that medium exhibit little statistically significant connection with offline civic activity. More specifically, those who monitor Snapchat posts frequently experience a 3.9-point rise in civic engagement apart from that outlet, while those who sometimes engage in politically oriented chatting experience a 3.04-point higher level of activity away from that medium. Respectively, these higher levels of engagement are the equivalent of performing one activity very often that previously did not happen, or performing one activity frequently that previously did not occur.

Conversely, the results in Table Two show higher levels of offline civic engagement associated with sending pictures and sending videos on Snapchat. Altogether, these results suggest that those activities that are expressive in nature and require sharing content beyond chatting are connected with higher levels of offline civic activity while the passive, consumptive activity of monitoring political activity on Snapchat usually are not.

We examine the results in Table Two in greater detail through Figure One to illustrate the effect estimates from these results. The top visual corresponds to sending political pictures while the bottom visual corresponds to sending political videos on Snapchat. In each illustration, the vertical axis is the ATET while the horizontal axis is the frequency with which each activity was performed. The solid line denotes the ATET while the dashed lines are the $95 \%$ confidence interval surrounding those effects.

The results from Table Two as visualized through Figure One demonstrate several trends. First, the ATETs for sending pictures or videos on Snapchat rise as students perform correspondingly higher 
levels of these activities. More specifically, those who sent pictures about candidates for office, political interest groups or political parties via Snapchat experienced approximately six-point higher levels of offline engagement if they did this activity either frequently or very often. This equates to participating in one additional civic activity away from the internet that otherwise would not have occurred very often and participating in another activity at a higher rate. This could also equate to participating in several different civic activities at higher levels.

Also, those who sent videos about political interest groups, candidates for office, or political parties on Snapchat experienced approximately four point higher levels of civic engagement if they sometimes did this activity, and by roughly seven points if they did this activity either frequently or very often. This suggests that sending videos on Snapchat has a greater effect on civic activity than sending pictures did. Practically speaking, this means having participated in one additional civic activity away from the internet that otherwise would not have happened very often. For those who sent videos frequently or very often, this also entails having participated in at least one other activity at a higher rate or participating in several different civic activities at higher levels.

However, those who sent pictures or videos about candidates for office, political interest groups or political parties via Snapchat rarely experienced no changes in civic activity. Altogether, both Snapchat activities that represent an active desire to share politics with others - posting political pictures or videos about politics - yield higher levels of civic engagement. Thus, those students who post political pictures or videos about politics at relatively high rates on Snapchat are the ones that experience higher levels of offline civic activity.

\section{Snapchat vs Facebook}

While the results furnish evidence that posting political pictures and videos about politics on Snapchat is connected with higher levels of offline civic engagement, one can ask how Snapchat compares in this respect to other, more established social media forms like Facebook. This comparison is important for two reasons. First, this comparison speaks to the relative uniqueness of Snapchat compared with other social media outlets. Second, this comparison allows us to compare a social media outlet that 
has a faster tempo (like Snapchat) with one that has a comparatively slower temporal order (like Facebook). This comparison is theoretically relevant for our analysis because information processing proceeds at a faster rate with a forum that features disappearing content, relative to one where content changes at slower rates, increasing the incentive for others to view the material shared before it disappears.

To perform this comparison, we examine activity on Facebook in an analogous way that we did for activities on Snapchat. Using a five-point scale that ranged from zero for never having never done so to four for having performed these activities very often, we asked respondents about the extent to which they had shared images or webpages related to a candidate for political office, political party, or an interest group on that outlet $(\mathrm{M}=1.21, \mathrm{SD}=1.38)$. When we compare the frequencies at which respondents participated in these activities on Facebook with those at which students shared politically-oriented pictures and videos on Snapchat, we find that, students were far less apt to share content on Snapchat than they were via Facebook. More specifically, $74.5 \%$ of student never shared politically oriented pictures on Snapchat, nor had $82.1 \%$ shared politically-oriented video on Snapchat. Conversely, only $46.56 \%$ of students never reported having shared pictures and webpages on Facebook. This makes sense because Facebook has been around approximately seven years longer than Snapchat, and is more embedded into popular culture than Snapchat. This means that a majority of students reported having engaged in politically-oriented activities at some level on Facebook ${ }^{17}$

We build on these trends by conducting a matching analysis using the same technique that we had with the four Snapchat variables through Tables One and Two. ${ }^{18}$ To do so, we created four binaries to

\footnotetext{
${ }^{17}$ Table D7 contains the complete comparison of activity levels on Snapchat versus those on Facebook.

18 The data for this variable satisfy the matching assumptions that existed in the previous estimations. In particular, each treatment is binary, there is no interference, and there are no hidden variations of the treatment because of the way in which we coded the treatment variables. In addition, each individual's assignment to one of the Facebook treatments is unconnected with their level of offline civic engagement, given the values of the remaining covariates.
} 
correspond to differing treatment levels that are coded in the same fashion as we did for the four Snapchat variables. In addition, the dependent variable (offline civic engagement) is the same, as are the covariates on which matching occurs.

\section{[TABLE THREE ABOUT HERE]}

Table Three displays the results for the Facebook analysis. We find that sharing webpages or pictures sometimes on Facebook is associated with an approximately three point rise in offline civic activity, a more than four-point rise in this activity when it occurs frequently, and a greater than seven point surge when this activity happens very often. For those who engaged in sharing webpages or pictures on Facebook frequently or very often, this equates to a minimum of having engaged in one additional offline civic activity very often that otherwise would not have happened. For those who sometimes engaged in sharing pictures of webpages on Facebook, this corresponds to offline civic activities being performed at higher rates than they otherwise would have.

\section{[FIGURE TWO ABOUT HERE]}

Through Figure Two, we compare the results from the analyses in Table Two with those in Table Three. The vertical axis is the ATET for each level of the treatment being examined, while the horizontal axis is the frequency of each activity (sending pictures on Snapchat, sending videos on Snapchat, and sharing pictures and webpages on Facebook). Further, the solid line corresponds to sharing webpages or pictures on Facebook; the dotted line corresponds to sending videos on Snapchat; and the dashed line corresponds to sending pictures on Snapchat. Three trends emerge from these analyses. First, the ATETs are positively associated with the frequency of each activity. Second, those who send videos on Snapchat consistently engage in higher levels of offline civic activity relative to those who share pictures and

Further, we satisfy the common support assumption because students could have opted out of having engaged in politically-oriented Facebook activities. Finally, we satisfy the SUTVA assumption because offline civic activity does not vary with sharing webpages or pictures on Facebook, as the correlation between these variables is .49. This correlation is sufficiently low such that we can say that we fulfill the SUTVA assumption. 
webpages on Facebook, especially if they do so regularly. Third, those who send pictures on Snapchat experience similarly higher levels of civic activity as those who do so on Facebook when they do so regularly and very often.

Finally, we verified whether the matching results that we report in are model-dependent (see Ho, Imai, King, and Stuart, 2007). A limitation of many matching analyses is the danger of p-hacking in which one can vary the functional form of the matching algorithm to produce a pattern of results that happens to confirm a researcher's insights (Head et al, 2015). To verify whether this concern arises in this analysis, we re-ran the matching routines by excluding one matching variable at a time. The results are contained in Appendix $\mathrm{C}$ and contain a total of 180 functional forms.

Of these functional forms, 160 of them (or $88.9 \%$ ) are identical in terms of the signs and significance patterns as those that are reported here. Of the 20 that differ from what are reported here, eight of them are situations in which we found statistical significance in the robustness check, but were not significant in the analyses we report. The remaining twelve them (or, $60 \%$ of the remainder) are in cases that are not significant in the robustness check where this analysis reports statistical significance. These twelve do not exhibit a pattern that contradicts what we report here. Finally, $93.3 \%$ of the models contained in the robustness checks either support the results or provide evidence that is even stronger than is reported here.

\section{Discussion and Conclusion}

In sum, political uses of Snapchat yield higher levels of civic engagement and provide direct evidence that Evan Spiegel's desire for Snapchat to have a larger role in mobilizing voters has worked. Thus, a medium that many may dismiss as inconsequential due to some of the triviality that occurs there ends up having significant, positive effects on civic engagement patterns among younger voters. Our findings fit nicely into the extant literature on the effects of social media on civic engagement, especially among younger voters. Many scholars have discovered that the activities that occur on Facebook and Twitter yield higher levels of online and offline civic engagement, particularly among young adults (Cantijoch et al, 2016; Conroy et al, 2012; Gil de Zuniga et al, 2012; Rice et al, 2013; Towner, 2013; 
Xenos et al, 2014). The results presented here show the effects of sharing political information on Snapchat equal or even surpass that of sharing political information on Facebook.

Yet, the results are consistent with our argument that the mechanism by which Snapchat use facilitates higher levels of civic activity is different than that of other social media platforms. The evidence suggests that sending videos or pictures about interest groups, political parties or candidates for office heightens other forms of civic and political activity. This effect is strongest among those who do so frequently or very often. Yet, monitoring Snapchat content from candidates for office, political parties, or political interest groups is not connected with much of a statistically significant change in civic engagement. Our results suggest that the same activities that are most easily dismissed on the surface as trivial or frivolous are also the ones associated with higher levels of civic engagement.

As with all political science research, our study has some limitations and implications. One limitation is that we use cross-sectional data to produce our findings. This approach allows for a possibility that may manifest itself here: college students who were already civically engaged are also more apt to use Snapchat in politically-oriented ways. While matching helps us deal with this possibility through comparing various Snapchat uses by individuals who are otherwise similarly predisposed to civic engagement, it does not fully eliminate this explanation. Others can use longitudinal data on college students to more effectively deal with this limitation, as there are ways of dealing with causality with longitudinal data that are not possible with cross-sectional data. For example, a longitudinal study would make the direction of causality clearer because it enables researchers to compare civic engagement levels at two points in time and see whether greater Snapchat use at the first time point produces increases in civic engagement at the second time point.

What is more, we investigated the effects of Snapchat on civic engagement using data that came from a single college campus. Thus, we may model campus-specific effects that do not generalize beyond the data. This limitation is prescient though, as matching analyses estimate quantities that are localized due to the nature of that statistical technique (see Imbens and Rubin, 2015). There is little data that are 
localized enough and of sufficient quality to be able to adequately model the effects of political activity on Snapchat on offline civic activity. A survey at a single college campus fulfills these requirements.

We are also confident that the findings of our research generalize beyond the university that we analyze for two reasons. First, the sex of students at this university is similar to that of the median comprehensive public university in the state in which it is located $(54.18 \%$ female at this university vs $55.7 \%$ female at median comprehensive public university). ${ }^{19}$ Second, the percentage of whites at this University $(72.8 \%)$ is somewhat similar to that which exists at the median comprehensive public university in the state in which it is located $(65.7 \%)$. More broadly, students at this university participate at rates that are similar to those at colleges and universities around the United States, as voter turnout was $3.5 \%$ higher at this university than the mean turnout for all colleges and universities in the 2016 general election (National Study of Learning, Voting, and Engagement, 2017). However, future research should investigate whether Snapchat also helps increase civic engagement among young adults not enrolled in college as Flanagan and Levine (2010) identify clear gaps in participation between young adults who attend college and those who do not.

Bimber (2003) cautions against focusing on the impact of specific technologies, as they can be fleeting. Yet, our theoretical arguments and findings in support of them are broader than Snapchat itself. They suggest that other, future social media platforms with similar features that help encourage creative political expression would produce similarly higher levels of civic engagement. In addition, future research should consider the impact of disappearing content more directly than our data allows. Because shared content disappears quickly, recipients are encouraged to pay it more attention, which also might encourage users to prefer it as a method of political expression. Yet, promoting political expression may raise concerns about Snapchat's impact on polarization. Here, the literature is mixed. Political discussions

\footnotetext{
${ }^{19}$ We acquired data on the other public comprehensive universities in this state from their websites for the Fall 2016 semester, except for two. For one of the two, we used data from the Fall 2017 semester, while we used data for the Fall 2015 semester for the other.
} 
on social media have been characterized as echo chambers in the media and some research supports this characterization (Barbera et al, 2015; Bashky et al, 2015). Communication in echo chambers can solidify partisanship and political views (Rudolph, 2011), strengthening partisan polarization at the national level (Klar, 2014). This might suggest Snapchat use by young adults could worsen polarization. However, Boxtell, Genzkow and Shapiro (2017) find that polarization in the public is more prevalent among those groups least likely to use social media. Thus, Snapchat use by younger voters could act as a limiting, rather than contributing factor in the growth of polarization in American politics.

Another area for future research lies in investigating who uses Snapchat for political purposes. Achen and Bartels (2016) suggest that voting behavior is more connected with group identity than with traditional conceptions of a democratic ethos. We do not directly test whether the use of Snapchat or behaviors on social media form differ by group identity because our goal is smaller scale: to examine whether activities on Snapchat are linked with higher levels of civic activity, broadly speaking. Since we have established a link between civic activity and behaviors on Snapchat, even after accounting for ideology and strong partisanship, this analysis provides the logical grounding for others to investigate whether the use of Snapchat or activity levels on that social media outlet are connected with group identities like party, race, and gender.

While much remains left to discover about political uses of Snapchat, including the possibility of indirect links between consumptive uses of Snapchat and civic engagement, our findings have implications for those who run political campaigns and those concerned about young adults' civic engagement levels. More specifically, those campaigns that engage voters via Snapchat can successfully engage young people. To accomplish this, though, campaigns need to encourage their Snapchat base to share videos and pictures related to candidates, parties, and interest groups. Amusing filters, doodles, stickers, and bitmojis help do so. This also means that campaigns should provide shareworthy, salient material that generates meaningful reactions. By doing so, campaigns can engage a group of voters that many chide for their low levels of participation. In addition, those at colleges and universities who wish to encourage civic engagement should promote it as a venue for political expression. Student affairs staff, 
faculty, and members of student government and organizations who care about generational discrepancies in participation might consider creative ways to encourage students to send political pictures and videos via Snapchat. By doing so, they can help improve students' overall rates of civic engagement. This fosters a democratic society because it gives meaningful opportunities for all to participate, and not just the usual suspects (Verba, et al, 1995). 


\section{References}

Abadie, A. and Imbens, G.W. (2006). Large Sample Properties of Matching Estimators for Average Treatment Effects. Econometrica, 74, 235-267.

Abadie, A. and Imbens, G.W. (2011). Bias-Corrected Matching Estimators for Average Treatment Effects. Journal of Business and Economic Statistics, 29, 1-11.

Abadie, A. and Imbens, G.W. (2016). Matching on the Estimated Propensity Score. Econometrica, 84, 781-807.

Abadie, A. and Spiess, J. (2016). Robust Post-Matching Inference. (Unpublished Paper, MIT and Harvard University). Retrieved from https://editorialexpress.com/cgi-bin/conference/download.cgi? db_name=EEAESEM2016\&paper_id=3067.

Achen, C. and Bartels, L. (2016). Democracy for Realists: Why Elections do not Produce Responsive Government. Princeton, NJ: Princeton University Press.

Barbera, B., Jost, J.T., Nagler, J., Tucker, J.A., and Bonneau, R. (2015). Tweeting From Left to Right: Is Online Political Communication More Than An Echo Chamber? Psychological Science, 26, $1531-1542$.

Bashky, E., Messing S., and Adamic, L. (2015). Exposure to ideologically diverse news and opinion on Facebook. Science, 348, 1130-1132.

Best, S.J. and Krueger, B.S. (2005). Analyzing the Representativeness of Internet Political Participation. Political Behavior, 27, 183-216.

Bimber, B. (2003). Information and American Democracy: Technology in the Evolution of Political Power. Cambridge, UK: Cambridge University Press.

Boorstin, J. (2016). Facebook, Snapchat and Twitter Played a Bigger Role than Ever in the Election. Last modified November 8, 2016. http://www.cnbc.com/2016/11/08/facebook-snapchat-andtwitter-played-a-bigger-role-than-ever-in-the-election.html. 
Boxtell, L., Gentzkow, M., and Shapiro, J.M. (2017). Greater Internet use is not Associated with Faster Growth in Political Polarization among U.S. Demographic Groups. Proceedings of the National Academy of Sciences of the United States of America, 114, 10612-10617.

boyd, d. (2014). Why Snapchat is Valuable: It's All About Attention. Last modified March 21, 2014. https://www.linkedin.com/pulse/20140321152822-79695780-why-snapchat-is-valuable-it-sall-about-attention.

Bump, P. (2015). Why 2016 will not be the Snapchat election. Last modified October 2, 2015. https://www.washingtonpost.com/news/the-fix/wp/2015/10/02/why-2016-will-not-be-thesnapchat-election/?utm_term=.07f59f240c0f.

Cantijoch, M., Cutts, D., and Gibson, R. (2016). Moving Slowly up the Ladder of Political Engagement: a 'Spill-over' Model of Internet Participation. British Journal of Politics and International Relations, 18, 26-48.

Chittal, N. (2015). 2016 candidates turn to Snapchat to announce their campaigns. Last modified June 16, 2015. http://www.msnbc.com/msnbc/2016-candidates-turn-snapchat-announce-their-campaigns.

Conroy, M., Feezell, J.T., and Guerrero, M. (2012). Facebook and Political Engagement: A Study of Online Political Group Membership and Offline Political Engagement. Computers in Human Behavior, 28, 1535-1546.

D’Agostino, R.B. (1998). Tutorial in Biostatistics: Propensity Score Methods for Bias Reduction in the Comparison of a Treatment to a Non-Randomized Control Group. Statistics in Medicine, 17, 2265-2281.

Dalton, R.J. (2008). The Good Citizen: How a Younger Generation is Reshaping American Politics. Washington, D.C.: CQ Press.

Diamond, A. and Sekhon, J.J. (2013). Genetic Matching for Estimating Causal Effects: A General Multivariate Matching Method for Achieving Balance in Observational Studies. Review of Economics and Statistics, 95, 932-945. 
Duggan, M. (2015). Mobile messaging and social media 2015. Last modified August 19, 2015. http://www.pewinternet.org/2015/08/19/mobilemessaging-and-social-media-2015-main-findings/.

Eggers, A.C. and Hainmueller, J. (2009). MPs for Sale? Returns to Office in Postwar British Politics. American Political Science Review, 103, 513-533.

Erkulwater, J.L., Schlozman, K.L., Verba, S., Brady, H.E. (2012). Political Participation over the Life Cycle. In The Unheavenly Chorus: Unequal Political Voice and the Broken Promise of American Democracy, by K.L. Schlozman, S. Verba, and H.E. Brady, pp. 199-231. Princeton: Princeton University Press.

Flanagan, C. and Levine, P. (2010). Civic Engagement and the Transition to Adulthood. Future of Children, 20, 159-179.

Flavin, P. and Griffin, J.D. (2009). Policy, Preferences, and Participation: Government's Impact on Democratic Citizenship. The Journal of Politics, 71, 544-559.

Flynn, K. (2016). Snapchat provided the rawest look at election night 2016. Last modified November 9, 2016. http://mashable.com/2016/11/09/snapchat-election/\#pWbf2h3blEql.

Friesleben, S. (2016). Donald Trump and Hillary Clinton through the eyes of Snapchat Users. Last modified September 27, 2016. https://www.cbsnews.com/news/donald-trump-hillary-clintonpresidential-debate-snapchat-filters-win-the-night/.

Gelman, A. and Hill, J. (2007). Data Analysis Using Regression and Multilevel/Heiarchical Models. New York, NY: Cambridge University Press.

Giglietto, F. and Selva, D. (2014). Second screen and participation: A content analysis on a full season dataset of tweets. Journal of Communication, 64, 260-277.

Gil de Zuniga, H.; Jung, N., and Valenzuela, S. (2012). Social Media Use for News and Individuals' Social Capital, Civic Engagement and Political Participation. Journal of Computer-Mediated Communication, 17, 319-336. 
Gil De Zuniga, H., Bachmann, I., Hsu, S., and Brundidge, J. (2013). Expressive Versus Consumptive Blog Use: Implications for Interpersonal Discussion and Political Participation. International Journal of Communication, 7, 1538-1559.

Hartman, R. (2017). “CFA in Laavan.” Last modified January 3, 2018. http://www.understandingdata.net/2017/03/22/cfa-in-lavaan.

Head, M.L., Holman, L., Lanfear, R., Kahn, A.T., and Jennions, M.D. (2015). The Extent and Consequences of P-Hacking in Science. PLoS Biology, 13, e1002106.

Ho, D.E., Imai, K., King, G., and Stuart, E.A. (2007). Matching as Nonparametric Preprocessing for Reducing Model Dependence in Parametric Causal Inference. Political Analysis, 15, 199-236.

Holbein, J. B. and D. Sunshine Hillygus, D.S. (2016). Making Young Voters: The Impact of Preregistration on Youth Turnout. American Journal of Political Science 60, 364-382.

Imbens, G.W. and Rubin, D.B. (2015). Causal Inference for Statistics, Social, and Biomedical Sciences: An Introduction. New York, NY: Cambridge University Press.

Jennings, M.K. and Niemi, R.M. (1981). Generations and Politics. Princeton, N.J.: Princeton University Press.

Kahneman, D. (1973). Attention and Effort. Englewood Cliffs, N.J.: Prentice Hall.

Kenski, K. and Stroud, N.J. (2006). Connections Between Internet Use and Political Efficacy, Knowledge, and Participation. Journal of Broadcasting and Electronic Media, 50, 173-192.

Kerbel, M.R. and Bloom, J.D. (2005). Blog for America and Civic Involvement. International Journal of Press/Politics, 10, 3-27.

King, G., Lucas, C., and Nielsen, R.A. (2017). The Balance-Sample Size Frontier in Matching Methods for Causal Inference. American Journal of Political Science, 61, 473-489.

Klar, S. (2014). Partisanship in a Social Setting. American Journal of Political Science, 58, 687-704.

Kuiper, N.A. and Robers, T.B. (1979). Encoding of Personal Information: Self-Other Differences. Journal of Personality and Social Psychology, 37, 499-514. 
Lapowsky, I. (2015). Sorry Snapchat, But You're Not Winning This Election. Last modified August 20, 2015. https://www.wired.com/2015/08/not-the-snapchat-election/.

Mahler, J. (2015). Campaign Coverage via Snapchat Could Shake Up the 2016 Elections. Last modified May 3, 2015. https://www.nytimes.com/2015/05/04/business/media/campaign-coverage-viasnapchat-could-shake-up-the-2016-elections.html?_r=0.

McGuire, W.J. (1978). An Information Processing Model of Advertising Effectiveness. In H.L. Davis and A.J. Silk (Eds.), Behavioral and Management Science in Marketing (pp. 156-180). New York, NY: Wiley.

Miller, W. E. and Shanks, J. M. (1996). The New American Voter. Cambridge, MA: Harvard University Press.

Miller, E.J. (2016). Donald Trump Launches Debate-Day Snapchat Filter Against ‘Crooked Hillary.' Last modified September 25, 2016. http://time.com/4507101/presidential-debate-donald-trumpsnapchat/.

Mitchell, A.A. (1983). Cognitive Processes Initiated by Exposure to Advertising. In R.J. Harris (Ed.), Information-Processing Research in Advertising (pp. 171-177). Hillsdale, N.J.: Lawrence Erlbaum Associates.

Moffett, K.W. and Rice, L.L. (2016). Web 2.0 and the Political Mobilization of College Students. Lanham, MD: Lexington Press.

Moffett, K.W. and Rice, L.L. (2018). College Students and Online Political Expression During the 2016 Election. Social Science Computer Review, 36, 422-439.

National Study of Learning, Voting and Engagement (2018). Survey Results for 2016 Election. Last modified January 19, 2018. https://idhe.tufts.edu/nslve.

Nichols, A. (2007). Causal Inference with Observational Data. The Stata Journal, 7, 507-541. 
Norris, P. (2002). Do Campaign Communications Matter for Civic Engagement? American Elections from Eisenhower to G.W. Bush. In D.M. Farrell and R. Schmitt-Beck (Eds.), Do Political Campaigns Matter?: Campaign Effects in Elections and Referendums (pp. 119-136). New York, NY: Routledge Press.

Nusca, A. (2017). Snapchat: An Abridged History. Last modified February 4, 2017. http://fortune.com/2017/02/04/snapchat-abridged-history/.

Pew Research Center for the People and the Press (2016). Flashpoints in Polling. Last modified October 24, 2016. http://www.pewresearch.org/2016/08/01/flashpoints-in-polling/.

Piper, N. (2016). Snapchat Lures More Campaign Spending as Candidates Court Young Voters. Last modified August 25, 2016. https://www.bloomberg.com/news/articles/2016-08-25/snapchatlures-more-campaign-spending-as-candidates-court-young-voters.

Piwek, L. and Joinson, A. (2016). What do they Snapchat about? Patterns of use in Time-Limited Instant Messaging Service. Computers in Human Behavior, 54, 358-367.

Putnam, R.D. (2000). Bowling Alone: The Collapse and Revival of American Community. New York, NY: Simon and Schuster.

Rice, L.L., Moffett, K.W., and Madupalli, R. (2013). Campaign-Related Social Networking and the Political Participation of College Students. Social Science Computer Review, 31, 257-279.

Rosenstone, S. and Hansen, J.M. (1993). Mobilization, Participation and Democracy in America. New York, NY: Macmillan Press.

Rossell, Y. (2012). Lavaan: An R Package for Structural Equation Modeling. Journal of Statistical Software, 48, 1-36.

Rudolph, T.J. (2011). The Dynamics of Ambivalence. American Journal of Political Science, 55, 561-573.

Rutenberg, J. (2016). In This Snapchat Campaign, Election News Is Big and Then It's Gone. Last modified April 24, 2016. https://www.nytimes.com/2016/04/25/business/media/snapchatelection-campaign-news.html. 
Sekhon, J.S. (2011). Multivariate and Propensity Score Matching Software with Automated Balance Optimization: The Matching Package for R. Journal of Statistical Software, 42, 1-52.

Shah, D.V., Kwak, N., and Holbert, R.L. (2001) “Connecting” and "Disconnecting” with Civic Life: Patterns of Internet Use and the Production of Social Capital. Political Communication, 18, $141-162$.

Shah, D.V., McLeod, J.M.; and Lee, N.J. (2009). Communication competence as a foundation for civic competence: Processes of socialization into citizenship. Political Communication, 26, 102117.

Snapchat (2016). Advertising Page. Last modified December 31, 2016. https://www.snapchat.com/ads. Stuart, E.A. (2010). Matching Methods for Causal Inference: A Review and a Look Forward. Statistical Science, 25, 1-21.

Towner, T.L. (2013). All Political Participation Is Socially Networked?: New Media and the 2012 Election. Social Science Computer Review, 31, 527-541.

Tulip, S. (2016). Try on Hillary Clinton's Pantsuit with these Election Snapchat Filters. Last modified November 7, 2016. http://college.usatoday.com/2016/11/07/hillary-clinton-election-snapchatfilters/.

Utz, S., Muscanell, N., and Khalid, C. (2015). Snapchat Elicits More Jealousy than Facebook: A Comparison of Snapchat and Facebook Use. Cyberpsychology, Behavior, and Social Networking, $18,141-146$.

Vacarri, C., Chadwick, A., and O’Loughlin, B. (2015). Dual screening the political: Media events, social media, and civic engagement. Journal of Communication, 65, 1041-1061.

Vaterlaus, J.M., Barnett, K., Roche, C., and Young, J.A. (2016). 'Snapchat is More Personal': An Exploratory Study on Snapchat Behaviors and Young Adult Interpersonal Relationships. Computers in Human Behavior, 62, 594-601.

Verba, S., Brady, H.E., and Schlozman, K.L. (1995). Voice and Equality: Civic Voluntarism in American Democracy. Cambridge, MA: Harvard University Press. 
Verstraete, G. (2016). It's about Time. Disappearing Images and Stories in Snapchat. Image and Narrative, 17, 104-113.

Wattenberg, M.P. (2011). Is Voting for Young People? $3^{\text {rd }}$ ed. New York, NY: Pearson Longman.

Wortham, J. (2013). A Growing App Lets You See It, Then You Don't. Last modified February 8, 2013. http://www.nytimes.com/2013/02/09/technology/snapchat-a-growing-app-lets-you-see-it-thenyou-dont.html.

Xenos, M., Vromen, A., and Loader, B.D. (2014). The Great Equalizer? Patterns of Social Media and Youth Political Engagement in Three Advanced Democracies. Information, Communication and Society, 17, 151-167.

Zukin, C., Keeter, S., Andolina, M., Jenkins, K. and Delli Carpini, M. X. (2006). A New Engagement? Political Participation, Civic Life, and the Changing American Citizen. New York, NY: Oxford University Press. 
Figure One: Effects of Sending Political Pictures and Political Videos via Snapchat on Civic Engagement

\section{Pictures}

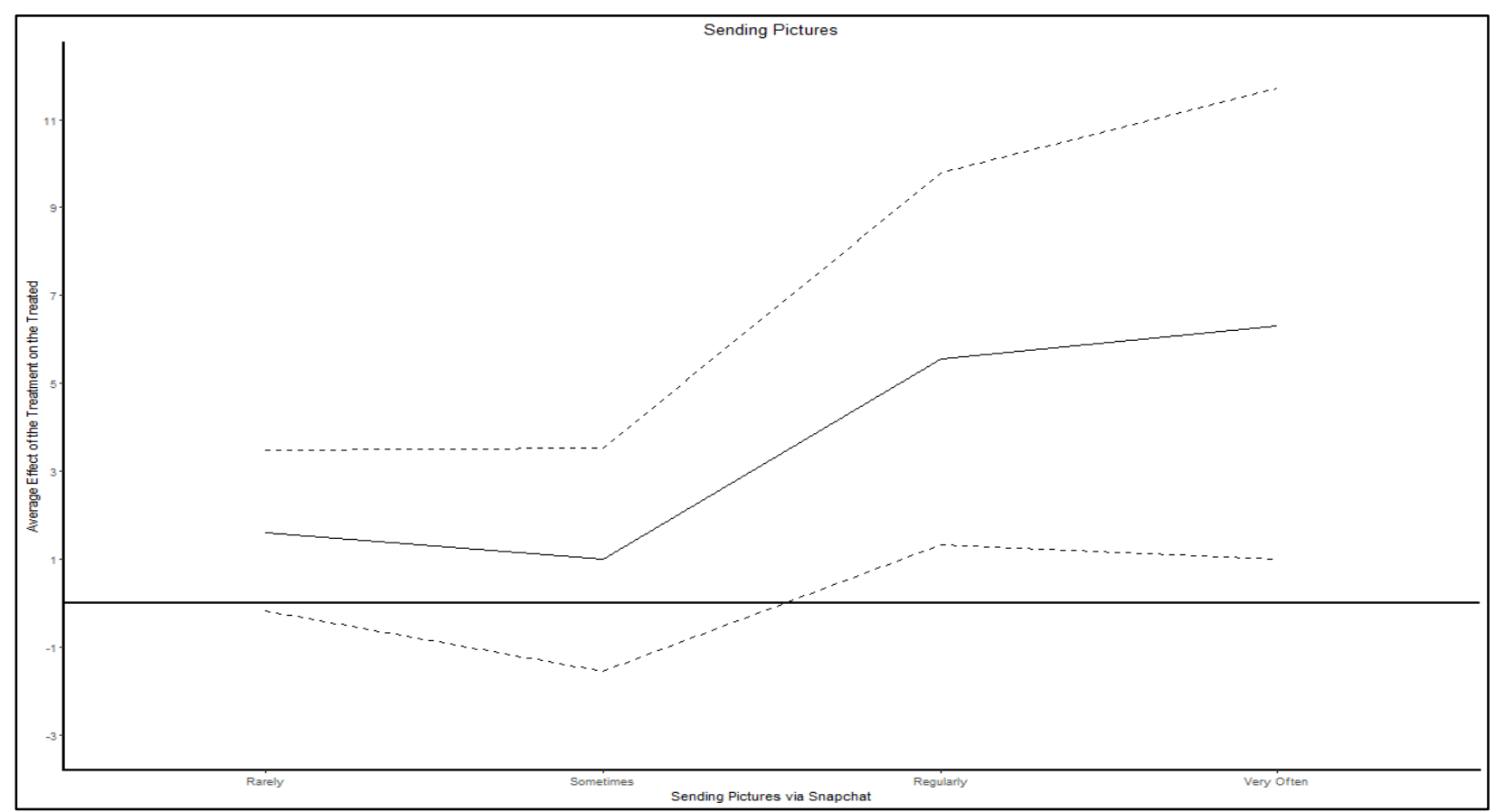

Videos

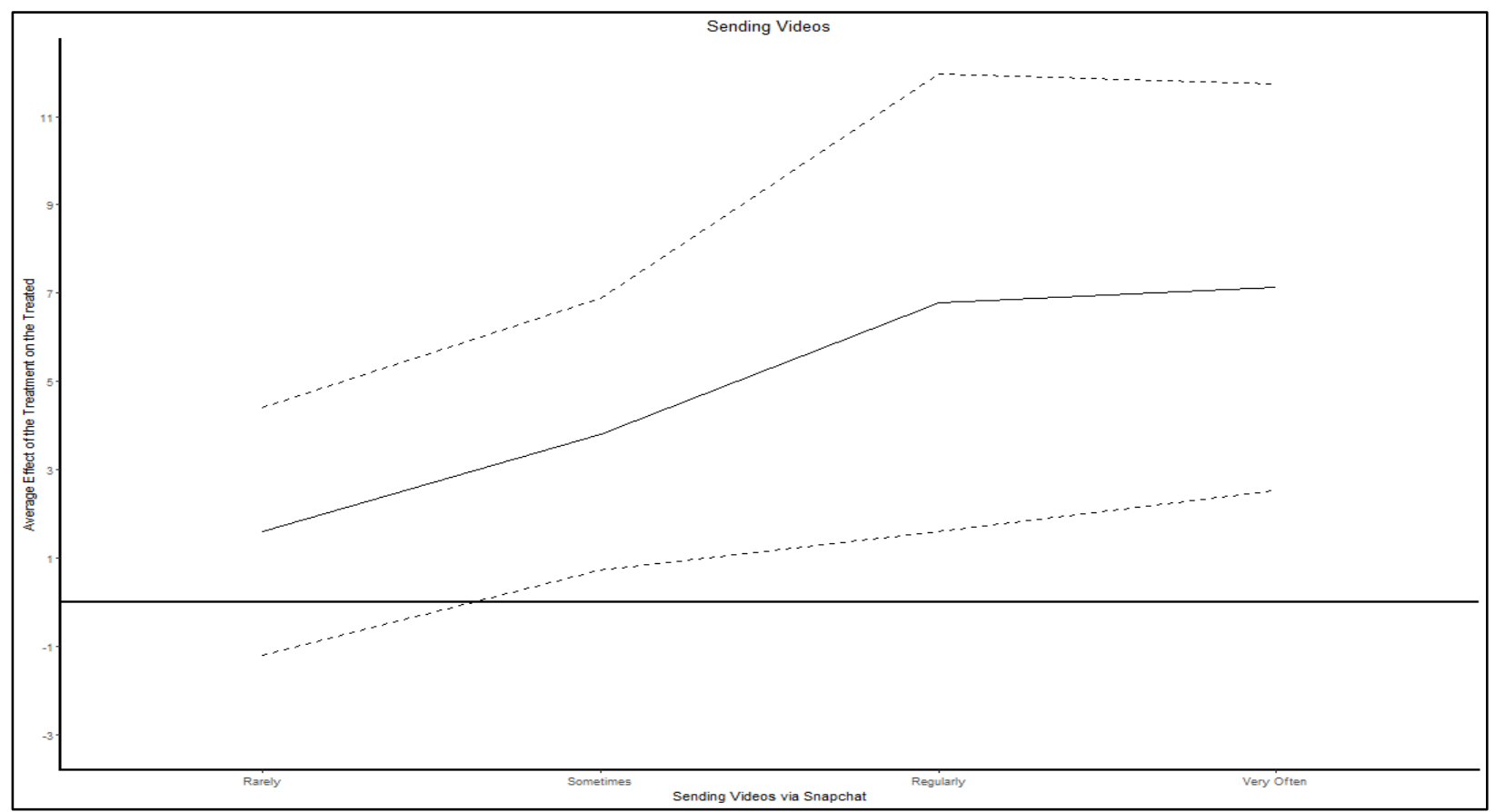

Notes: The solid lines denote the average treatment effect on the treated (ATET) while the dashed lines denote the $95 \%$ confidence interval around these estimates. 
Figure Two: Comparison between Sending Pictures and Videos on Snapchat versus Activity on Facebook

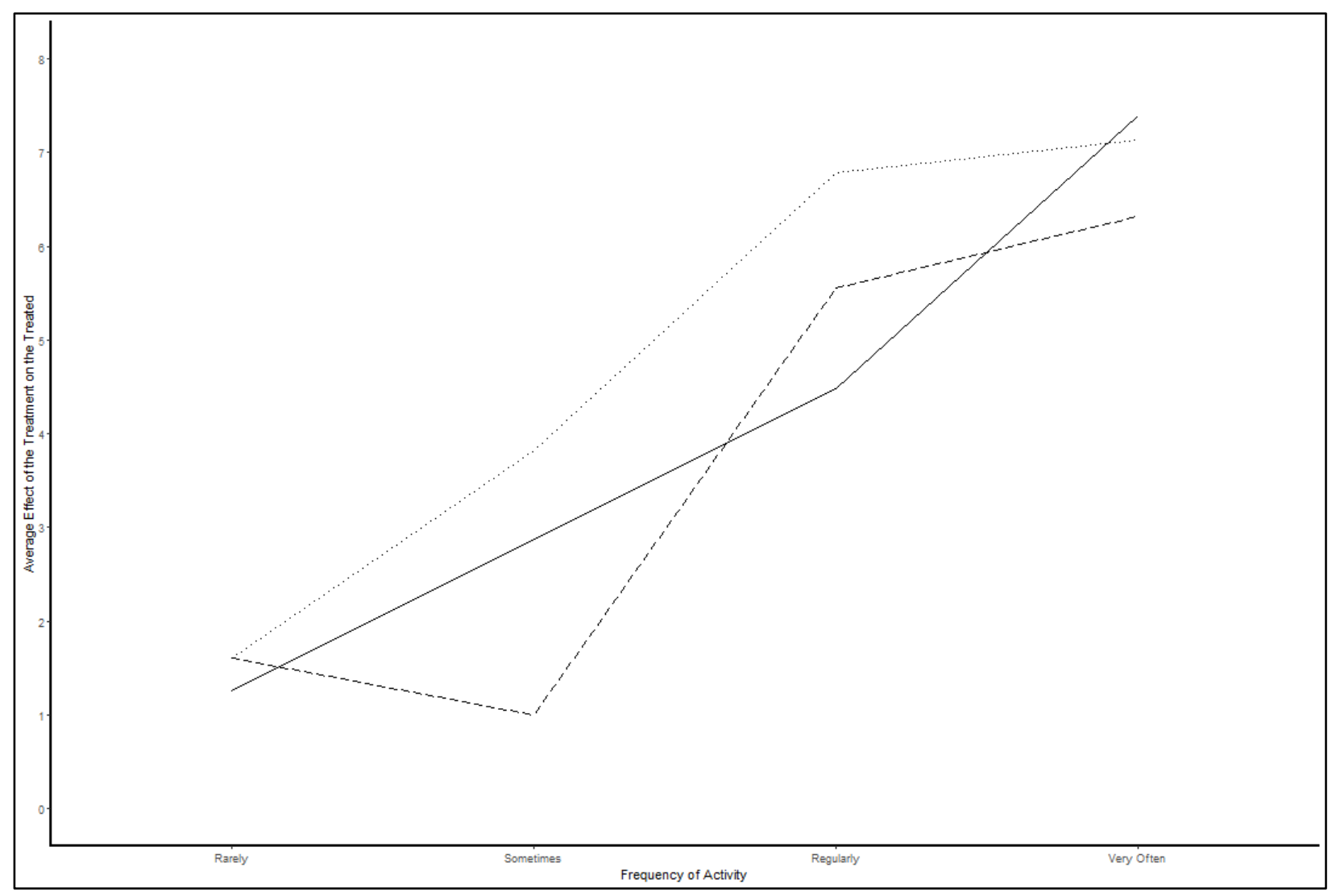

Note: The dashed line corresponds to sending pictures on Snapchat. The dotted line corresponds to sending videos on Snapchat. Finally, the solid line corresponds to sharing pictures and webpages on Facebook. 
Table One: Matching Estimates of Monitoring Snapchat Posts and Politically-Oriented Chatting on Offline Engagement

\begin{tabular}{|c|c|c|c|c|c|c|c|c|}
\hline & \multicolumn{3}{|c|}{ Monitoring Snapchat Posts } & \multicolumn{3}{c|}{ Politically-Oriented Chatting } \\
\hline & Rarely & $\underline{\text { Sometimes }}$ & $\underline{\text { Frequently }}$ & $\underline{\underline{\text { Very }}}$ & $\underline{\text { Rarely }}$ & $\underline{\text { Sometimes }}$ & Frequently & $\underline{\text { Very Often }}$ \\
\hline $\begin{array}{c}\text { Effect on } \\
\text { Offline Civic } \\
\text { Engagement }\end{array}$ & -.487 & .942 & 3.884 & 3.261 & -.624 & 3.043 & 2.674 & 2.925 \\
\hline $\begin{array}{c}\text { Abadie- } \\
\text { Imbens } \\
\text { Standard } \\
\text { Error }\end{array}$ & 1.011 & 1.479 & 1.512 & 2.029 & 1.234 & 1.257 & 2.615 & 5.334 \\
\hline $\begin{array}{c}95 \% \\
\text { Confidence } \\
\text { Interval } \\
\text { Lower Bound }\end{array}$ & -2.509 & -2.025 & .825 & -.971 & -3.106 & .532 & -2.765 & -8.442 \\
\hline $\begin{array}{c}95 \% \\
\text { Confidence } \\
\text { Interval } \\
\text { Upper Bound }\end{array}$ & 1.535 & 3.909 & 6.943 & 7.493 & 1.858 & 5.554 & 8.113 & 14.292 \\
\hline $\begin{array}{c}\text { T-Statistic } \\
\text { P-Value }\end{array}$ & -.487 & .637 & 2.569 & 1.607 & -.506 & 2.421 & 1.023 & .548 \\
\hline N & 60 & .524 & .010 & .108 & .613 & .015 & .306 & .584 \\
\hline
\end{tabular}

Notes: In each two-column set, the level of monitoring is compared with those who never did so. Second, the covariates on which the matching is based are described in the text. Third, the effects on offline civic engagement are the average treatment effect for the treated (ATET). Finally, the matching results are from 1:1 genetic matching with post-matching bias adjustment. Thus, the $\mathrm{N}$ represents the matched number of observations. 
Table Two: Matching Estimates of Sending Videos and Pictures via Snapchat on Offline Engagement

\begin{tabular}{|c|c|c|c|c|c|c|c|c|}
\hline & \multicolumn{4}{|c|}{$\underline{\text { Sending Pictures }}$} & \multicolumn{4}{|c|}{$\underline{\text { Sending Videos }}$} \\
\hline & Rarely & $\underline{\text { Sometimes }}$ & Frequently & $\begin{array}{l}\text { Very } \\
\text { Often }\end{array}$ & Rarely & $\underline{\text { Sometimes }}$ & Frequently & Very Often \\
\hline $\begin{array}{c}\text { Effect on } \\
\text { Offline Civic } \\
\text { Engagement }\end{array}$ & 1.608 & .998 & 5.555 & 6.317 & 1.603 & 3.819 & 6.786 & 7.136 \\
\hline $\begin{array}{l}\text { Abadie- } \\
\text { Imbens } \\
\text { Standard } \\
\text { Error }\end{array}$ & .936 & 1.265 & 2.037 & 2.523 & 1.358 & 1.512 & 2.478 & 2.178 \\
\hline $\begin{array}{c}95 \% \\
\text { Confidence } \\
\text { Interval } \\
\text { Lower Bound }\end{array}$ & -.278 & -1.547 & 1.330 & 1.016 & -1.194 & .742 & 1.600 & 2.540 \\
\hline $\begin{array}{c}95 \% \\
\text { Confidence } \\
\text { Interval } \\
\text { Upper Bound }\end{array}$ & 3.494 & 3.543 & 9.780 & 11.718 & 4.400 & 6.896 & 11.972 & 11.732 \\
\hline T-Statistic & 1.717 & 1.579 & 2.727 & 2.504 & 1.181 & 2.526 & 2.738 & 3.277 \\
\hline P-Value & .086 & .114 & .006 & .012 & .238 & .012 & .006 & .001 \\
\hline $\mathrm{N}$ & 45 & 48 & 23 & 19 & 26 & 34 & 19 & 18 \\
\hline
\end{tabular}

Notes: In each two-column set, the level of monitoring is compared with those who never did so. Second, the covariates on which the matching is based are described in the text. Third, the effects on offline civic engagement are the average treatment effect for the treated (ATET). Finally, the matching results are from 1:1 genetic matching with post-matching bias adjustment. Thus, the $\mathrm{N}$ represents the matched number of observations. 
Table Three: Matching Estimates of Sharing Pictures and Webpages via Facebook on Offline Engagement

\begin{tabular}{|c|c|c|c|c|}
\hline & \multicolumn{4}{|c|}{ Sharing on Facebook } \\
\hline & $\underline{\text { Rarely }}$ & $\underline{\text { Sometimes }}$ & $\underline{\text { Frequently }}$ & $\underline{\underline{\text { Very }}}$ \\
& & & & \\
\hline Eften \\
\hline Abadie-Imbens Standard Error & .776 & .843 & 1.234 & 1.335 \\
\hline 95\% Confidence Interval Lower Bound & -.281 & 1.204 & 2.012 & 4.724 \\
\hline $95 \%$ Confidence Interval Upper Bound & 2.799 & 4.548 & 6.944 & 10.056 \\
\hline T-Statistic & 1.622 & 3.412 & 3.630 & 4.813 \\
\hline P-Value & .105 & .001 & .0003 & $<.0001$ \\
\hline $\mathrm{N}$ & 98 & 107 & 65 & 67 \\
\hline
\end{tabular}

Notes: In each two-column set, the level of monitoring is compared with those who never did so. Second, the covariates on which the matching is based are described in the text. Third, the effects on offline civic engagement are the average treatment effect for the treated (ATET). Finally, the matching results are from 1:1 genetic matching with post-matching bias adjustment. Thus, the $\mathrm{N}$ represents the matched number of observations. 